\title{
Scrub typhus in pregnancy-a case series with variable presentation from mild to severe disease
}

\author{
Seema Sheokand*, Anju Singh, Pradip K. Saha, Manisha Meena
}

Department of Obstetrics and Gynecology, Postgraduate Institute of Medial Education and Research, Chandigarh, India

Received: 15 December 2020

Accepted: 15 January 2021

\section{*Correspondence:}

Dr. Seema Sheokand,

E-mail: seemasheokand001@gmail.com

Copyright: (c) the author(s), publisher and licensee Medip Academy. This is an open-access article distributed under the terms of the Creative Commons Attribution Non-Commercial License, which permits unrestricted non-commercial use, distribution, and reproduction in any medium, provided the original work is properly cited.

\begin{abstract}
Scrub typhus is an uncommon cause of acute febrile illness during pregnancy. It can lead to adverse maternal and fetal outcomes if not diagnosed early and treated appropriately. It manifests as mild febrile disease to severe form with multiorgan dysfunction. It might be clinically difficult to diagnose scrub typhus, hence it is important that those presenting with an acute febrile illness in endemic regions should have targeted investigations for early detection. Here we present successful management of three cases of scrub typhus in pregnancy with variable presentation of scrub typhus. Two of these presented in antenatal period whereas one in postnatal period resembling abdominal tuberculosis all three were tested COVID-19 (real time polymerase chain reaction) negative.
\end{abstract}

Keywords: Pregnancy, Scrub typhus, Stillbirth, Multiorgan dysfunction

\section{INTRODUCTION}

The tsutsugamushi triangle, is the region in world which extends from the Northern Japan and far East Russia in the North to Northern Australia in the South and to Pakistan in the West is well known where scrub typus is endemic and India is an integral component of this triangle. ${ }^{1}$ Scrub typhus is caused by $O$. tsutsugamushi and is spread by bite by trombiculid mites. Clinical spectrum varies from mild self-limiting to fatal form. ${ }^{2}$ It is characterized by fever, an exanthemata's rash, myalgia and diffuse lymphadenopathy. Complications like sepsis, shock, hepatitis, acute respiratory distress syndrome (ARDS), pre renal azotemia and multi-organ dysfunction syndrome (MODS) are seen in untreated cases. There is significant vascular leakage and end-organ injury due to disseminated vasculitis and perivascular inflammatory lesions. Sometimes, palpable spleen and liver may also be present. In untreated cases mortality rate ranges from 7 $30 \% .^{3}$

\section{CASE SERIES}

\section{Case 1}

A 26 years old primigravida came to emergency at 28 weeks period of gestation (POG) with fever for 3 days, with documentation of $101-102^{\circ} \mathrm{F}$. There was no history of cough, dyspnea, jaundice, skin rash, joint pains, vomiting, diarrhea, loss of appetite, altered bowel habits, urinary symptoms or bleeding manifestations. She had regular ante-natal checkups. Antenatal period and investigations were normal till date. On general physical examination the patient was conscious and coherent. Her pulse was 99/minute, blood pressure 110/70 $\mathrm{mmHg}$, temperature $100.8^{\circ} \mathrm{F}$ and respiratory rate $20 / \mathrm{min}$. Abdominal examination was normal with fetal growth corresponding to period of gestation age. Ultrasonography done showed single live pregnancy corresponding to 28 gestational weeks with placenta previa. A peripheral smear for malaria, serology for dengue, leptospirosis and scrub typus, blood and urine 
culture were sterile. In work up of topical fever, scrub typhus came out to be positive and tablet azithromycin $500 \mathrm{mg}$ once daily given for 5 days. Patient responded in 48 hours, became afebrile and discharged in stable condition. After 3 weeks she again presented to emergency with episode of heavy menstrual bleeding and caesarean section done at 31 weeks with live born baby weighing $1500 \mathrm{gm}$.

\section{Case 2}

A 29 years old with three living issue referred at day 27 postpartum with history of fever of $100-102^{\circ} \mathrm{F}$ for 10 days and generalized abdominal pain with distension for last 5 days. There was no history of vomiting, jaundice, altered bowel habits or foul-smelling discharge. Her antenatal period was irregularly supervised but intrapartum period was uneventful. Her vitals were stable. But abdominal distension with shifting dullness was present. Her per speculum and vaginal examination were normal. Ultrasonography of abdomen suggested of hepatomegaly and moderate ascites. Differentials considered were puerperal sepsis with pyoperitoneum, abdominal Koch or some liver pathology. Straw colored ascitic fluid analysis had leukocyte count of 533 with $73 \%$ of polymorphs, with protein level of 2.9 and sugar of $53 \mathrm{mg} / \mathrm{dl}$, ADA was 25 and CBNAAT of ascitic fluid negative. All cultures of blood, urine, ascetic fluid, cervical swab was sterile. Chest X-ray had minimal right sided pleural effusion and sputum for tuberculosis was negative. Contrast enhanced computed tomography (CECT) abdomen and pelvis showed hepatomegaly with ascites with abdominal lymphadenopathy. In work up for tropical fever scrub typus report was positive. Patient treated initially with injectables Piptaz and clindamycin considering it to be postpartum sepsis, later started on oral doxycycline 100 mg twice daily for 14 days and discharged in stable condition after 4 days.

\section{Case 3}

A 30-Year-old woman gravida 2 with previous one preterm lower segment caesarean section was referred with a history of nausea vomiting and epigastric pain for 3 days at 31 weeks period of gestation. There was history of dyspnea, jaundice, skin rash for 2 days but no history of fever. She had regular ante-natal checkups and was referred from a peripheral health center as gallstone related pancreatitis. There was no history of hypertension or deranged blood sugar. On general physical examination there was mild pallor, icterus and skin rash at left lower limb. Her pulse 100/minute, blood pressure $110 / 70 \mathrm{mmHg}$, temperature $98.8^{\circ} \mathrm{F}$, and respiration rate 30/min, dyspnea present. Cardiovascular, respiratory, neurological were normal. On per abdominal examination, there was tenderness in epigastrium and right hypochondrium, Pfannenstiel scar seen, uterine size corresponding to 28 weeks of gestation with cephalic presentation and relaxed. Fetal heart sound was not audible by stethoscope which was confirmed by ultrasonography. ABG ( $\mathrm{pH}-7.20, \mathrm{pCO}_{2}-22.7, \mathrm{pO}_{2}-78.8$, $\mathrm{HCO}_{3}-8.8$, B.E.-17.8), suggestive of uncompensated metabolic acidosis, ECG, chest X-ray and 2D ECHO were normal. Abdominal ultrasonography showed hepatosplenomegaly with mild right pleural effusion and pancreas was normal. Differentials considered were acute cholangitis related pancreatitis or AFLP (Swansea criteria-7), septic shock or tropical illness with stage 3 AKI with IUFD. As per institutional protocol for fever of unknown origin a peripheral smear for malaria, serology for dengue leptospirosis and scrub typus, blood and urine culture were sterile. Immunochromatographic assay for scrub typus was done which turned out to be positive.

Table 1: Investigations on admission.

\begin{tabular}{|c|c|c|c|c|}
\hline Investigation & $\begin{array}{l}\text { Case } \\
1\end{array}$ & $\begin{array}{l}\text { Case } \\
2\end{array}$ & $\begin{array}{l}\text { Case } \\
3\end{array}$ & $\begin{array}{l}\text { Normal } \\
\text { range }\end{array}$ \\
\hline $\begin{array}{l}\text { Hemoglobin } \\
\text { (g/dl) }\end{array}$ & 10 & 6.7 & 10.1 & $13-16$ \\
\hline $\begin{array}{l}\text { Platelets } \\
\left(\times 10^{9} / 1\right)\end{array}$ & 1.5 & 2.92 & 30,000 & $150-400$ \\
\hline $\begin{array}{l}\text { Total leukocyte } \\
\text { count }\left(\times 10^{9} / 1\right)\end{array}$ & 11 & 10.6 & 16,600 & $4-12$ \\
\hline $\begin{array}{l}\text { Bilirubin } \\
\text { (mg/dl) }\end{array}$ & 0.4 & 0.62 & 8.5 & $0.2-1$ \\
\hline ALP (U/I) & 165 & 469 & 532 & $30-150$ \\
\hline AST (U/l) & 48 & 32 & 396 & $10-40$ \\
\hline ALT (U/I) & 50 & 23 & 58 & $10-40$ \\
\hline $\begin{array}{l}\text { Albumin } \\
\text { (gm/dl) }\end{array}$ & 3.8 & 1.58 & 2.8 & $3.5-5.5$ \\
\hline $\begin{array}{l}\text { Amylase } \\
\text { (units/I) }\end{array}$ & 16 & 20 & 660 & $30-110$ \\
\hline Lipase (units/I) & 12 & 15 & 328 & $0-160$ \\
\hline PT & 14 & 19.6 & 19.2 & $\begin{array}{l}\text { Control- } \\
14\end{array}$ \\
\hline PTI & $98 \%$ & $63 \%$ & $72 \%$ & $\begin{array}{l}\text { Control- } \\
85-100 \%\end{array}$ \\
\hline APTT (seconds) & 32 & 35 & 37.3 & $\begin{array}{l}\text { Control- } \\
32\end{array}$ \\
\hline $\begin{array}{l}\text { Sodium } \\
(\mathrm{mmol} / \mathrm{l})\end{array}$ & 138 & 140 & 129 & $135-145$ \\
\hline $\begin{array}{l}\text { Potassium } \\
(\mathrm{mmol} / \mathrm{l})\end{array}$ & 4.1 & 3.2 & 4.9 & $3.5-5.5$ \\
\hline Urea (mg/dl) & 20 & 28 & 127 & $15-40$ \\
\hline $\begin{array}{l}\text { Creatinine } \\
(\mathrm{mg} / \mathrm{dl})\end{array}$ & 0.9 & 0.38 & 2.83 & $<1.3$ \\
\hline $\begin{array}{l}\text { ESR (mm in } \\
\text { first hour) }\end{array}$ & 20 & 40 & 50 & $<10$ \\
\hline CRP (mg/l) & 55 & 190 & 220 & $<5$ \\
\hline $\begin{array}{l}\text { Procalcitonin } \\
(\mathrm{ng} / \mathrm{ml})\end{array}$ & 0.8 & 0.2 & 7.7 & $<0.5$ \\
\hline $\begin{array}{l}\text { Lactate } \\
(\mathrm{mmol} / \mathrm{l})\end{array}$ & 1 & 2.8 & 6 & $0.5-1$ \\
\hline
\end{tabular}

ALP, alkaline phosphatase; AST, aspartate transaminase; ALT, alanine transaminase; PT, prothrombin time; APTT, activated partial thromboplastin time; ESR, erythrocyte sedimentation rate; CRP, C-reactive protein 
Further dyspnea aggravated with severe metabolic acidosis, multiorgan dysfunction and shock patient was intubated and started on triple inotropes (noradrenaline, vasopressin and adrenaline). In view of AKI, oliguria and metabolic acidosis underwent hemodialysis and was started on broad spectrum antibiotic Piptaz in renal modified dose along with injection doxycycline in suspicion of tropical fever. She received multiple platelet transfusions for thrombocytopenia. Patient vitals improved and inotropes gradually tapered and augmentation of labour done with Pitocin in view of intrauterine fetal demise. She delivered vaginally stillborn baby followed by mild atonic postpartum hemorrhage. Patient received five cycles hemodialysis and there was gradual improvement in vitals, urine output and extubated after 7 days, later progressively normalized laboratory parameters discharged under stable condition (Table 1).

\section{DISCUSSION}

There has been a recent increase in prevalence of scrub typhus worldwide and in India. Scrub typhus is a disease with clustering of cases are witnessed mainly in July to October months, namely in the monsoon and post monsoon seasons ('post monsoon surge'). ${ }^{4}$ All three cases presented in monsoon season.

Eschar has been considered pathogenic of scrub typhus infection, although compared to global literature, India reports fewer number of patients $(8-15 \%)$ with eschar formation. ${ }^{5}$ The cause can be mostly attributed to the dark complexion of the inhabitants and lower degree of suspicion of the disease among the physicians. For the laboratory diagnosis of scrub typhus, IgM ELISA was used which carries a sensitivity of $96 \%$ and specificity of $99 \% .^{5}$

The infection of Orientia tsutsugamushi is characterized pathologically by focal or disseminated vasculitis and perivasculitis on the involved organs. ${ }^{6}$ Gastrointestinal manifestations like abdominal pain, nausea, vomiting, hematemesis and diarrhea, are seen in approximately $25 \%$ of patient with scrub typus. ${ }^{7}$ Aung-Thu et al in his study reported that abdominal pain may be due to vasculitis of the gastrointestinal tract in scrub typhus infection. $^{7}$ Therefore, this should be considered in differential diagnosis of fever and abdominal pain in endemic area. Case 2 had history of fever and abdominal pain followed by ascites.

The liver injury manifests in the form of jaundice and elevation of the transaminase enzymes. Kanno et al suggested that liver pathology in scrub typhus is consistent with the features of reactive hepatitis and cellular immunity is the causative factor. ${ }^{8}$ A combination of elevated transaminases, thrombocytopenia, leukocytosis and deranged renal function test has role to play in diagnosis of scrub typhus. ${ }^{9}$ In one Taiwan study, found $89.3 \%$ had elevated aspartate aminotransferase
(AST) levels, $91.7 \%$ with elevated alanine aminotransferase (ALT) levels, 84.2\% with elevated alkaline phosphatase (ALP) levels and $38.5 \%$ with elevated total bilirubin levels. ${ }^{10}$ In our case 3 , there is a close relationship between scrub typhus and impaired liver function tests. Therefore, if patients are found with fever of unknown origin and abnormal liver function, we should take scrub typhus into consideration. Park et al studied prevalence of various abdominal CT findings of scrub typhus in 94 patients these were, enlarged lymph node $(53.2 \%)$, in homogeneous enhancement of liver (47.9\%), splenomegaly (46.8\%), ascites (28.7\%) similar to case 2 , that had associated lymphadenopathy on CT. ${ }^{11}$

Also, hyponatremia is the most common electrolyte abnormality seen. The reason behind hyponatremia may be multiple including sodium loss, ATPase activity, increased level of $\mathrm{ADH}$ (anti diuretic hormone) and osmo-receptor resetting. A study by Hullatti and various other studies conducted all over India from different states also reveal similar biochemical spectrum as shown in the third case of present study. ${ }^{12}$

Renal involvement in scrub typhus infection presents low grade albuminuria, microscopic hematuria and pyuria on urinalysis in majority, suggesting predominant tubulointerstitial involvement. The underlying pathophysiology of acute kidney injury in scrub typhus can be attributed as a part of multi organ dysfunction syndrome due to overwhelming sepsis, decreased renal perfusion due to volume depletion and increased vascular permeability. ${ }^{13}$

ARDS is another major and fatal complication of scrub typhus clinical profile and delay in use of appropriate antibiotics can lead to mortality rates up to $25 \% .{ }^{14}$ Third case in the series had this serious complication culminating into intubation and prolonged intensive care stay. This infection causes direct endothelial cell invasion causing diffuse alveolar damage with hyaline membrane and interstitial pneumonitis with infiltration of inflammatory cells. Cases manifesting with cough, dyspnea, raised white blood cell counts, increased hematocrit or total bilirubin are at increased risk of developing ARDS. ${ }^{14}$

The fetal complication associated with this are increased incidences of fetal loss, pre-term delivery and small for gestational age. ${ }^{15,16}$ In our study one had (case 2) preterm delivery while case 3 had intrauterine fetal demise.

Diagnosis of scrub typhus is challenging as its symptoms mimic with other acute febrile illnesses. The method recommended by CDC (center for disease control and prevention) is species-specific quantitative real time polymerase chain reaction targeting corresponding outer membrane protein and was the method of diagnosis in all three cases.

The recommended treatment regimen for scrub typhus is doxycycline $100 \mathrm{mg}$ bd for 7-15 days in non-pregnant 
female while in pregnancy azithromycin is the drug of choice. ${ }^{17}$ The fatal outcome was attributed to the delayed presentation of patients with multiple organs involvement. Early diagnosis of these cases resulted in less severe organ damage and easy recovery with antibiotics.

\section{CONCLUSION}

Early diagnosis and treatment with doxycline/ azithromycin results in a favorable outcome for both the mother and fetus.

Funding: No funding sources

Conflict of interest: None declared

Ethical approval: Not required

\section{REFERENCES}

1. Longo DL, Fauci AS, Kasper DL, Hauser SL, Jameson JL, Loscalzo J, editors. Harrison's Principle of Internal Medicine. $18^{\text {th }}$ ed. USA: The McGrawHill Companies; 2012;1064-65.

2. Premraj SS, Mayilananthi K, Krishnan D, Padmanabhan K, Rajasekaran D. Clinical profile and risk factors associated with severe scrub typhus infection among non-ICU patients in semi-urban south India. J Vector Borne Dis. 2018;55:47-51.

3. Rajapakse S, Rodrigo C, Fernando D. Scrub typhus: pathophysiology, clinical manifestations and prognosis. Asian Pac J Trop Med. 2012;5:261-4.

4. Mathai E, Rolain JM, Verghese GM, Abraham OC, Mathai D, Mathai M et al. Outbreak of scrub typhus in Southern India during the cooler months. Ann N Y Acad Sci. 2003;990:359-64.

5. Mahajan SK. Scrub Typhus. J Assoc Physicians India. 2005;53:954-8.

6. Walker DH, Mattern WD. Rickettsial vasculitis. Am Heart J. 1980;100:896-906.

7. Thu-A, Suparanond W, Phumiratanaprapin W. Gastrointestinal manifestations of septic patients with scrub typhus in Maharat Nakhon Ratchasima
Hospital. Southeast Asian J Trop Med Public Health. 2004;35:845-51.

8. Kanno A, Yamada M, Murakami K. Liver involvement in tsutsugamushi disease Tohoku. J Exp Med. 1996;179:213-17.

9. Rapsang AG, Bhattacharyya P. Scrub typhus. Indian J Anaesth. 2013;57(2):127-34.

10. $\mathrm{Hu} \mathrm{Ml}$, Liu JW, Wu LK, Lu SH, Chiou SS, Kuo CH et al. Abnormal liver function in scrub typhus. Am J Trop Med Hyg. 2005.73(4):667-8.

11. Park MJ, Lee HS, Shim SG, Kim SH. Scrub typhus associated hepatic dysfunction and abdominal CT findings. Pak J Med Sci. 2015;31(2):295-9.

12. Hullatti C, Latha GS, Babu VBV. Hyponatremia: a diagnostic marker for the diagnosis of Rickettsial diseases. Int J ContempPediatr. 2017;4:696-9.

13. Young PC, Hae CC, Lee KH, Hoon CJ. Tsutsugamushi infection-associated acute rhabdomyolysis and acute renal failure. Korean $\mathbf{J}$ Intern Med. 2003;18(4):248-50.

14. Wang CC, Liu SF, Liu JW, Chung YH, Su MC, Lin MC. Acute respiratory distress syndrome in scrub typhus. Am J Trop Med Hyg. 2007;76:1148-52.

15. Phupong V, Srettakraikul K. Scrub typhus during pregnancy: A case report and review of the literature Southeast Asian. J Trop Med Public Health. 2004;35:358-60.

16. Mathai E, Rolain JM, Verghese L, Mathai M, Jasper $P$, Verghese G. Scrub typhus during pregnancy in India: A case report. Trans R Soc Trop Med Hyg. 2003;97:570-72.

17. McGready R, Prakash JA, Benjamin SJ, Watthanaworawit W, Anantatat T, Tanganuchitcharnchai A. Pregnancy outcome in relation to treatment of murine typhus and scrub typhus infection: a fever cohort and a case series analysis. Trop Dis. 2014;8:e3327.

Cite this article as: Sheokand S, Singh A, Saha PK, Meena M. Scrub typhus in pregnancy-a case series with variable presentation from mild to severe disease. Int J Reprod Contracept Obstet Gynecol 2021;10:738-41. 